\title{
A PRESENÇA DE FEUERBACH NA LÓGICA DA FILOSOFIA
}

\author{
DE ERIC WEIL
}

\author{
Evanildo Costeski ${ }^{1}$
}

\section{Resumo}

A presença de Feuerbach na Categoria de Deus da Logique de la Philosophie (1950) de Eric Weil foi discutida pelos principais intérpretes da filosofia weiliana desde os anos 1970. De fato, não se pode negar em princípio tal influência. Tanto para Feuerbach como para Weil, Deus é uma projeção do homem e a teologia nada mais é que antropologia. Entretanto, isso não significa que não existem diferenças entre a posição de Feuerbach e a de Weil. É certo que, para Eric Weil, o finito produz o infinito, mas isso não denota que o infinito se reduz ao finito, tal qual defende Feuerbach. O discurso sobre Deus revela um Sentido infinito, não apreendido totalmente pelo homem finito. O que importa para Weil é a ideia de liberdade presente em todos os discursos humanos, inclusive no discurso teológico. Por isso, o discurso teológico não pode simplesmente ser ignorado pela filosofia. O presente artigo almeja destacar justamente as semelhanças e diferenças da posição da ideia de Deus em Weil em relação à concepçãode Feuerbach.

Palavras Chaves:Deus; Categoria; Liberdade; Sentido.

\begin{abstract}
The presence of Feuerbach in the Category of God of Logique de la Philosophie (1950) by Eric Weil was discussed by interpreters of weiliana philosophy since 1970. In fact, it cannot be denied in principle such influence. Both Feuerbach and for Weil, God is a projection of man and theology is nothing more than anthropology. However, this does not mean that there are not differences between the position of Feuerbach and the Weil. Admittedly, to Eric Weil, the finite produces infinity, but this does not denote that the infinite is reduced to finite, like Feuerbach advocate. The discourse on God reveals an infinite sense, not fully grasped by finite man. What matters to Weil is the idea of freedom present in all human discourse, even in theological discourse. Therefore, the theological discourse cannot simply be ignored by philosophy.This article aims precisely highlight the similarities and differences of idea of God in Weil in relation to Feuerbach.
\end{abstract}

Keywords: God; Category; Freedom; Sense.

A Lógica da filosofia de Eric Weil (1904-1977) é considerada uma das obras filosóficas mais impressionantes e complexas da segunda metade do século $\mathrm{XX}^{2}$. Ela tem a pretensão de compreender todos os discursos filosóficos produzidos pelo homem

\footnotetext{
${ }^{1}$ Possui graduação em Filosofia pela Universidade do Sagrado Coração, mestrado em Filosofia pela Pontifícia Universidade Gregoriana (1997) e doutorado em Filosofia pela Pontifícia Universidade Gregoriana (2004). Pós-doutorado no Centro de História e Cultura da Universidade Nova de Lisboa (2012). Professor Associado I da Universidade Federal do Ceará. Membro correspondente externo do Instituto Eric Weil (IEW) da Université Charles-de-Gaulle Lille 3. Coordenador do PIBID-Filosofia da UFC. Tem experiência na área de Filosofia, com ênfase em Filosofia da Religião, Filosofia brasileira e Filosofia Política, atuando principalmente nos seguintes temas: Ensino de Filosofia, Kierkegaard, Eric Weil, Agostinho da Silva, Violência, Religião e Relações Internacionais.

${ }^{2}$ Para uma interpretação sistemática da Lógica da Filosofia de Eric Weil, ver G. Kirscher (1989) e Marcelo Perine (2013).
} 
na história, através da articulação sistemática daquilo que Weil chama de atitudes/categorias. A atitude é o modo como o homem vive naturalmente no mundo: "O homem está no mundo (compreendido como aquilo no que ele vive) de determinada maneira, ele vive numa determinada atitude" (Weil, 2012, p. 105-106). Normalmente, o homem não se preocupa em compreender a sua atitude: ele simplesmente a vive. A filosofia não se apresenta para ele como a primeira de suas preocupações.

Enquanto expressão livre do homem no mundo, as atitudes são infinitas e, como tais, irredutíveis ao discurso filosófico. Todavia, é sempre possível a atitude humana passar a se compreender no discurso filosófico. De fato, "toda atitude pode ser transformada em discurso" e, mais especificamente, produzir uma categoria de acordo com sua própria natureza (Weil, 2012, p. 118). Mas isso não significa que a categoria contém todo o conteúdo da atitude. É verdade que, enquanto determinam o conteúdo das atitudes, as categorias têm primazia para o lógico da filosofia ${ }^{3}$, todavia, a Lógica da filosofiaexprime apenas a estrutura lógica e formal das categorias, não o conteúdo existencial das atitudes. Este permanece sempre indeterminado e, portanto, violento para o sistema filosófico. A atitude pode, perfeitamente, opor-se ao discurso filosófico e realizar-se, como tal, na linguagem incoerente do poeta ou, ainda, no puro silêncio, entendido como recusa consciente do lógos filosófico.

Ressalta-se que Weil não apresenta, na Lógica da filosofia,nenhuma diferença qualitativo-essencial de uma atitude/categoria em relação a uma outra atitude/categoria. Todas as dezesseis atitudes/categorias concretas da Lógica da filosofia (Verdade, NãoSenso, o Verdadeiro e o Falso, Certeza, Discussão, Objeto, Eu, Deus, Condição, Consciência, Inteligência, Personalidade, Absoluto, Obra, Finito, Ação) são igualmente importantes e necessárias para o sistema.Além dessas dezesseis atitudes/categorias concretas, a Lógica possui duas categorias formais, a saber, o Sentido e a Sabedoria, responsáveis pela constituiçãológica do sistema.

Pelo fato de ser uma lógica dos discursos filosóficos produzidos por atitudes humanas, a Lógica da filosofia não desenvolve uma teoria de um Ser transcendente aos discursos humanos, visto que "esse Ser só se mostra no discurso" e que "o discurso não sai jamais de si mesmo" (Weil, 2012, p. 101). Em relação ao discurso ontológico do Ser, é a Lógica da filosofiaque se apresenta como filosofia primeira:

\footnotetext{
${ }^{3}$ Chamamos de "lógico da filosofia" o filósofo que compreende a filosofia a partir da Lógica da filosofia de Eric Weil.
}

\begin{tabular}{|c|c|c|c|c|}
\hline Rovita Q Dialectus & Ano 2 & n. 6 & Janeiro - Agosto 2015 & p. $130-137$ \\
\hline
\end{tabular}


A filosofia primeira não é, portanto, uma teoria do Ser, mas o desenvolvimento do logos do discurso, para ele próprio e por ele próprio, na realidade da existência humana, que se compreende em suas realizações na medida em que ela quer se compreender. Ela não é ontologia, ela é lógica, não do Ser, mas do discurso humano concreto, dos discursos que formam o discurso em sua unidade (Weil, 2012, p. 105).

Diante disso, podemos perguntar: como as ideias de Deus, de fé e de religião podem ser compreendidas dentro da Lógica? Ora, se o discurso da Lógica de Weil não é uma teoria do Ser, é evidente que ela não pode tratar ontologicamente de Deus. Por isso, o capítulo sobre Deus da Lógica da filosofianão tem nada a ver com uma teologia filosófica. Deus não é para a Lógica um ser, mas uma categoria, isto é, um conceito organizador de um discurso, produzido por uma atitude particular, no caso, a atitude da fé (cf. Bouillard, 1989, p. 238). Mas como entender essa atitude?

Antes de tudo, é preciso assinalar que a fé que interessa a Weil não é a fé de uma religião positiva. Eric Weil quer captar a fé em sua pureza, longe de todo dogmatismo e de todo racionalismo teológico. O cristianismo, por exemplo, não pode ser pensado sem a teologia. Por isso, na atitude/categoria Deus, Weil se refere mais ao Antigo Testamento, onde é mais fácil apreender a fé em sua essência, entendida como sentimento religioso; sentimento que constitui o fundo do judaísmo e do islamismo e que, em sua vertente mística, teve também uma função muito importante no cristianismo (cf. Bouillard, 1989, p. 239).

O que interessa a Weil não é, portanto, o conteúdo teológico e racional da fé, mas mostrar "que a atitude da fé é sentimento e que sua linguagem é justamente a linguagem do sentimento" (Bouillard, 1989, p. 245), linguagem essa compreendida na Lógica como essencialmente poética e mitológica. Mas se a atitude da fé é basicamente sentimento, por que o crente diz que a origem da fé encontra-se em um Deus transcendente? Não teríamos aqui uma projeção do sentimento humano em um Ser transcendente, tal qual foi pensado e defendido por Feuerbach?

Apresença de Feuerbach na categoria Deus da Lógica da Filosofia foi defendidaem um importante artigo de Raymond Vancourt (1902-1978), publicado na revista Archives de Philosophie, em 1970. Como observa Vancourt, são várias as passagens da Lógica da Filosofia que lembram Feuerbach (1970, p. 480-481), apesar de Weil não citá-lo diretamente. Eis algumas: "Para nós (...), é sob a categoria de Deus que, pela primeira vez, o homem se vê e se interpreta na totalidade de sua vida” (p.

\begin{tabular}{|l|l|l|l|l|}
\hline Qenista Qialectus & Ano 2 & n. 6 & Janeiro - Agosto 2015 & p. 130-137 \\
\hline
\end{tabular}


266); “... é em sua fonte, em sua essência, em Deus que ele [o homem] compreende sua existência; e é em sua existência que essa essência se revela" (p. 266).Deus existe no coração do homem. "É verdade que o próprio crente vê o princípio em Deus, não em si mesmo. Mas, na realidade, é no crente que Deus existe" (p. 267). O filósofo sabe que Deus é apenas uma projeção do crente. É o homem que é o centro de tudo: "Esse fato, porém, não é visto pelo próprio crente: para ele, o centro é Deus, e o homem só se compreende em sua qualidade de criatura, ser vivo no mundo criado sob uma lei"'(p. 267). Para nós, isto é, para o filósofo que pensa a atitude do crente, o homem é aí tudo, mas, para o crente, Deus é tudo. O homem é apenas um reflexo de Deus. O que dizer de tudo isso? Eis o que afirma Vancourt:

No comportamento religioso, o homem projeta fora de si o arquétipo que ele gostaria de ser. Quando ele se compara a esse arquétipo, do qual ele é o autor, ele só pode se compreender como um reflexo dessa ideia, uma imagem deficiente em comparação ao modelo que ele mesmo criou. Ele não tem consciência que ele mesmo se despiu de seus atributos para transferi-los em um ideal divino criado por ele (1970, p. 481).

O que foi dito acima já é suficiente para ressaltar a presença de Feuerbach na categoria Deus. Entretanto, é importantelembrar que a categoria Deus não se refere diretamente ao Deus Cristão, mas ao monoteísmo em geral. Já Feuerbach, como sabemos, ocupa-se basicamentedo cristianismo. Para tratar do cristianismo na Lógica da Filosofia temos que ir para a categoria da Personalidade. É na Personalidade, compreendida a partir da retomadadaideia de Deus, que se encontra o núcleo da teologia cristã.

$\mathrm{Na}$ atitude/categoria Deuso sentimento humano é projetado em um ser ideal. Para a Personalidade, ao contrário, o sentimento é o homem mesmo. O problema é construir um discurso adequado para falar desse sentimento, visto que, para a atitude da Personalidade, o sentimento não pode ser determinado. O que existe é a presença total de si mesma, não como um outro do sentimento, mas como o sentimento mesmo (cf. Weil, 2012, p. 423).

Para falar de si mesma, a Personalidade passa a utilizar estrategicamente do discurso da categoria Deus, criando um aparente paradoxo na linguagem humana. Através da ideia de Deus, a Personalidade torna-se livre para viver segundo o seu próprio sentimento. É verdade que historicamente o homem alcança primeiro a personalidade divina, antes de se pôr como personalidade humana (cf. Weil, 2012, p.

\begin{tabular}{|l|l|l|l|l|}
\hline Qenista Dialectus & Ano 2 & n. 6 & Janeiro - Agosto 2015 & p. 130-137 \\
\hline
\end{tabular}


444); entretanto, para a Personalidade, se Deus se tornou homem,o homem também se tornou Deus.O conflitonão estaria mais na relação Deus-Homem, mas na própria atitude humana: "Tão logo o homem toma a responsabilidade do conflito para si tal como ele é, o Deus transcendente desaparece, céu e terra se confundem e já não há aquele momento decisivo em que o destino eterno da humanidade esteve em jogo no tempo" (Weil, 2012, p. 445-446). A fé deixa de ser voltada para um Deus transcendente, para se tornar "a fé do homem nele mesmo como criador de si a partir de seu passado" (Weil, 2012, p. 447). Com isso, o homem descobre "o seu próprio fundo", enquanto sentimento puro e imediato. A teologia e o dogma cristão foram de fato importantes para o homem descobrir a si mesmo; mas eles sempre foram discursos humanos. O segredo da teologia é a antropologia, tal como afirmou Feuerbach (2011, p. 5).

É claro que nem todos os filósofos concordam com essa solução. Kierkegaard, por exemplo, prefere manter o paradoxo do Deus-Homem em sua tensão existencial. Para Weil, enquanto persistir o paradoxo kierkegaardiano do Deus-Homem, o estado de crisenão pode ser plenamente compreendido pelo discurso filosófico (cf. Weil, 2012, p. 446). Não obstante,parece que Weil, em princípio, está realmente de acordo com Feuerbach. A ideia de Deus é de fato uma projeção do homem. Contudo, isso não significa que toda a verdade da fé se reduz a esta afirmação. Se é verdade que a ideia de Deus é uma projeção da fé do homem crente, é verdade também que o conceito defé não se reduz à ideia do Deus cristão.

Não podemos tomar aqui uma verdade parcial como o todo da verdade. É certo que o infinito é uma projeção do finito; porém, esta afirmação não é toda a verdade. É preciso continuar a trabalhar com a teologia, para se chegar à verdade antropológica da fé. O próprio Feuerbach percebeu isso, ao anunciar em suas Preleções que sua filosofiatem, "rigorosamente falando, uma única meta, um intento, um pensamento, um tema. Este tema é exatamente a religião e a teologia e tudo o que com isso se relacione". (Feuerbach, 2009, p. 18). A teologia pode de fato ser uma ilusão, mas esta ideiapode igualmente ser uma ilusão, criada por um discurso puramente empírico e técnico, típico do século XIX (cf. Paula, 2007, p. 162-163). Para o lógico da filosofia, o fato de Deus se apresentar como infinito mostra que a finitude não é a última realidade humana. A ideia de infinito tem o seu valor. Mas que infinito seria esse? E como ele poderia permanecer infinito, se na verdade é uma projeção do homem finito?

\begin{tabular}{|l|l|l|l|l|}
\hline Gevista Dialectus & Ano 2 & n. 6 & Janeiro - Agosto 2015 & p. 130-137 \\
\hline
\end{tabular}


É certo que Weil se apresenta como filósofo pós-cristão, mas nem por isso ele rejeita o cristianismo e a fé cristã. Se fizer isso, ele negará aquilo que consiste um dos núcleos principais de sua filosofia, a saber, a prática dodiálogo ${ }^{4}$. Com efeito, se o filósofo for simplesmente um ateu, ele rejeitará implicitamente toda a possibilidade de diálogo com os crentes e, por conseguinte, não poderá construir um discurso sensato para todos os homens (Olmi, 1986, p. 153).

É certo que para Weil o infinito não se identifica imediatamente nem com o Deus da revelação cristã nem com outro tipo de Ser transcendente. O que interessa a Weil é, sobretudo, a ideia de Sentido. Esta, diz Weil, "não é uma ideia inventada: ela está no fundo e no ponto de consumação de todo discurso humano" (Weil, 2012, p. 113). Todavia, não se pode negar que a ideia de Deus continua a ser importante para o discurso filosófico: esse sobresser indescritível, indizível, mas capaz de fundar toda descrição, todo discurso e todo ser (2012, p. 16). Desse modo, Deus deixa de ser para Weil um ser pessoal, para se tornar um ser anônimo, uma ideia de Sentido ou, simplesmente, “o eterno presente no tempo e na história” (cf. Bouillard, 1989, p. 309310).

Tal como afirmou Feuerbach, Deus não é, portanto,um ser separado. Ele é a própria essência do homem.No entanto, ao contrário de Feuerbach, Weil conserva a ideia de infinito produzida pela fé, afirmando que o homem finito só se compreende a partir do infinito (cf. Bouillard, 1989, p. 255).É dessa forma que oinfinito pode se apresentar para o homem finito através da atitude da fé. Trata-se aqui de um infinitonãoontológico, essencialmente formal, de uma Presença ausente, sem um conteúdo determinado, de um Sentido infinito, desejado como um fim a ser alcançado pelo discurso filosófico e por toda ação humana.

A atitude da fé da Lógica da filosofia conduz justamente a essa experiência de Sentido, expressa, no caso, por meio de um desejo de amor vivenciado pelas religiões monoteístas e que, enquanto sentimento, é do mesmo modo presente em todos os indivíduos, independentemente de sua experiência religiosa. Como afirma Michel Castro, professor da Universidade Católica de Lille, para Weil, pode-se perfeitamente falar deDeus-Sentido (cf. Castro, 2012, p. 213) ${ }^{5}$. Como dissemos, esse Sentido não pode

\footnotetext{
${ }^{4}$ Ver, por exemplo, o artigoVertu du dialogue (Weil, 1982, p. 279-295).

${ }^{5}$ Podemos interpretar todas as categorias-atitudes concretas da Lógica da Filosofia como retomadas (Schema) da categoria Sentido. Isso vale, especialmente, para a categoria Deus, haja vista a sua importância histórica para a reflexão filosófica moderna (cf. Costeski, 2009, p. 101-105).
}

\begin{tabular}{|l|l|l|l|l|}
\hline Renista Dialectus & Ano 2 & n. 6 & Janeiro - Agosto 2015 & p. 130-137 \\
\hline
\end{tabular}


apregoar um conteúdo objetivo ao homem. A fé que produz o Sentido não depende de um discurso exterior à própria fé. Kierkegaard percebeu isso claramente. Ele enfatizou "a fides qua em relação à fides quae" (Gouvêa, 2006, p. 148).Para o filósofo dinamarquês, o que importa não é o objeto da crença, a quae, mas a maneira de se crer, isto é, o como se crê. Todo discurso sobre Deus deve partir da interioridade da fé, da vivência do como ou, simplesmente, da fidesqua ${ }^{6}$.

Em Weil, obviamente, a atitude da fénão é originária da graça divina, como quer Kierkegaard e a teologia cristã.No entanto, Weil não deixa de reconhecer, assim como Feuerbach, a importância da teologia cristã para a compreensão do homem. É verdade que, para a teologia cristã, a fides qua não existe sem a gratuidade do próprio Deus. Porém, isso não significa que a compreensão da fé deve ser reduzida ao ponto de vista cristão. Ao aplicarmos a fides qua à atitude de fé weiliana, acabamos simplesmente por naturalizá-la. Segundo a nossa compreensão, todos os indivíduos têm, sem exceção, uma fé natural,particular e livre,que, como tal, pode se tornar, por exemplo, uma fé da razão,compreendida em sentido Kantiano,ou, ainda, uma fé transcendental religiosa, entendida em seu sentido teologal. Existe uma crença ou fé que precede e envolve todas as decisões teóricas (cf. Bouillard, 1989, p. 344). Todos os indivíduos expressam um ato de fé, ao tomarem uma decisão importante na vida. Isso vale outrossim para as decisões científicas e políticas. Desse modo, a fé não é realmente religiosa em seu início; porém, ela pode perfeitamente expressar-se em uma experiência religiosa, cristã ou não.É por isso que a Lógica da filosofiarespeita a liberdade presente nas várias manifestações históricas de fé, haja vista que todas são expressões do sentimento do homem e, como tais, necessárias para se pensar o Sentido e, enfim, fundar o próprio discurso filosófico.

A fé, portanto, não produz apenas ilusões, como quer Feuerbach. É verdade que sem a fé não existiriamas ilusões religiosas; mas, com certeza, tampouco existiriama filosofia, as ciências naturais, as ações políticas e todas as demais produções humanas. Sem a fé, o homem seria um animal, um robô ou até um Deus; mas,seguramente, não seria umhomem.

\footnotetext{
${ }^{6}$ Isso não significa dizer que Kierkegaard permanece indiferente ao objeto da crença. Ele acreditaem Cristo e na Bíblia. Isso foi enfatizado pelo filósofo e teólogo jesuíta Francês Henri Bouillard em um importante artigo sobre a fé em Kierkegaard (1963, p. 71). Coube ao grande intérprete francês de Kierkegaard H. B. Vergote reconhecer o mérito do artigo de Bouillard. Para Vergote, não se trata de privilegiar a fides qua creditur em detrimento da fides quae creditur, mas de encontrar o sentido da fides quae crediturna fides quacreditur(1982, vol. II, p. 86).
}

\begin{tabular}{|c|c|c|c|c|}
\hline Revista Aidectus & Ano 2 & n. 6 & Janeiro - Agosto 2015 & p. $130-137$ \\
\hline
\end{tabular}


Evanildo Costeski

\section{Referências Bibliográficas}

BOUILLARD, H. Philosophie et religion dans l'oeuvre d'Éric Weil. In: Vérité du christianisme. Paris: Desclée de Brouwer, 1989, p. 233-315.

BOUILLARD, H. La foi d'après Kierkegaard. In:Logique de la foi. Paris: Aubier, 1963.

CASTRO. M. L'itinéraire Théologique d'Henri Bouillard. De Thomas d'Aquin à Emmanuel Levinas. Paris: CERF, 2012.

COSTESKI, E. Atitude, Violência e EstadoMundial Democrático. Sobre a Filosofia de Eric Weil. São Leopoldo/Fortaleza: Unisinos/UFC, 2009.

FEUERBACH, L. A Essência do Cristianismo. Lisboa: Fundação Calouste Gulbenkian, 2011.

FEUERBACH, L. Preleções sobre a essência da religião. Petrópolis: Vozes, 2009.

GOUVÊA, R. Q. Paixão pelo paradoxo. Uma introdução a Kierkegaard. São Paulo: Fonte Editorial, 2006.

KIRSCHER, G. La philosophie d'Eric Weil. Systématicité et ouverture. Paris: Presses Universitaires de France, 1989.

OLMI, A. Dio come categoria. Saggio sulla Logique de la Philosophie di Eric Weil. Milão: Marzorati Editore, 1986.

PAULA, M. G. de. O futuro de uma ilusão: Algumas reflexões entre Feuerbach e

Freud. Revista AdVerbum,vol. 2, 2007, p. 161-171.

PERINE, M. Filosofia e Violência. Sentido e intenção da filosofia de Éric Weil. São Paulo: Loyola, 2013.

VANCOURT, R. Quelques remarques sur le problème de Dieu dans la philosophie d'Eric Weil. Archives de Philosophie, vol. 33, 1970, p. 471-489.

VERGOTE, H-B. Sens e Répétition. Essai sur l'ironie kierkegaardienne. Paris, CERF/ORANTE, Vol. II, 1982.

WEIL, E. Lógica da Filosofia. São Paulo: É Realizações, 2012.

WEIL, E. Vertu du dialogue. In: Philosophie et Réalité. Derniers essais et conférences. Paris: Beauchesne, 1982, p. 279-295.

\begin{tabular}{|c|c|c|c|c|}
\hline QRenista Dialectus & Ano 2 & n. 6 & Janeiro - Agosto 2015 & p. $130-137$ \\
\hline
\end{tabular}

